\title{
ANALISIS KEPUASAN PASIEN RAWAT JALAN TERHADAP PELAYANAN DI INSTALASI FARMASI RUMAH SAKIT BHAYANGKARA MANADO
}

\author{
Venesya Natalia Putri Kaunang ${ }^{1)}$, Gayatri Citraningtyas' ${ }^{2)}$, Widya Astuty Lolo ${ }^{3)}$ \\ ${ }^{1)}$ Program Studi Farmasi FMIPA UNSRAT Manado, 95115
}

\begin{abstract}
Patient satisfaction is an important indicator for service quality and has implications for the delivery of services more efficiently in meeting patient needs. A good quality of service will provide patients satisfaction to and it will affect patients to hospital if needed. The purpose of this study was to determine the satisfaction of outpatients with services in the Pharmacy Installation at the Bhayangkara Hospital in Manado. The type and design of the study used is a type of descriptive research with a cross-sectional approach. Patient satisfaction was measured using the SERVQUAL (Service Quality) method. The result of this study, tangible (-0.26), assurance (0-305), empathy (-0.37), responsiveness (-0.69), and the lowest is reliability (-0.86). It can be concluded that the overall satisfaction score is in the negative index, meaning that the patient is not satisfied with the services provided at the Pharmacy Installation.
\end{abstract}

Keywords: Patient Satisfaction, SERVQUAL, Pharmacy Installation, Bhayangkara Hospital Manado.

\begin{abstract}
ABSTRAK
Kepuasan pasien merupakan indikator penting bagi kualitas pelayanan dan memiliki implikasi bagi penyelenggaraan pelayanan lebih efisien dalam memenuhi kebutuhan pasien. Kualitas pelayanan yang baik akan memberikan kepuasan kepada pasien serta kepuasan pasien akan memengaruhi pasien untuk kembali lagi ke Rumah Sakit tersebut bila membutuhkan. Tujuan dari penelitian ini untuk mengetahui kepuasan pasien rawat jalan terhadap pelayanan di Instalasi Farmasi Rumah Sakit Bhayangkara Manado. Jenis dan rancangan penelitian yang digunakan adalah jenis penelitian deskriptif dengan pendekatan secara cross-sectional. Kepuasan pasien diukur menggunakan metode SERVQUAL (Service Quality). Hasil penelitian ini. secara berturut-turut yaitu reliability (-0.86), responsiveness (-0.69), emphaty (-0.37), assurance (0-305) dan yang terendah adalah tangible (-0.26) secara berturut-turut yaitu reliability (-0.86), responsiveness (-0.69), emphaty (-0.37), assurance (0-305) dan yang terendah adalah tangible (-0.26). Kesimpulannya yaitu nilai kepuasan secara keseluruhan berada pada indeks negatif, artinya bahwa pasien belum merasa puas terhadap pelayanan yang diberikan di Instalasi Farmasi.
\end{abstract}

Kata kunci : Kepuasan Pasien, SERVQUAL, Instalasi Farmasi, Rumah Sakit Bhayangkara Manado 


\section{PENDAHULUAN}

Kepuasan pasien merupakan indikator penting bagi kualitas pelayanan dan memiliki implikasi bagi penyelenggaraan pelayanan lebih efisien dalam memenuhi kebutuhan pasien. Berdasarkan definisi tersebut, kualitas pelayanan yang baik akan memberikan kepuasan kepada pasien serta kepuasan pasien akan memengaruhi pasien untuk kembali lagi ke Rumah Sakit tersebut bila membutuhkan. Pasien merasa puas, akan menguntungkan rumah sakit juga karena akan dipromosikan lewat mulut ke mulut oleh pasien yang telah merasakan pelayanannya.

Tingkat kepuasan pasien ditinjau dari lima dimensi SERVQUAL yakni dimensi keandalan (reliability), adalah pemberian informasi obat oleh petugas. Daya tanggap (responsiveness), terkait kecepatan pelayanan resep. Jaminan (assurance), kelengkapan obat dan harga obat. Empati (emphaty), adalah keramahan petugas terhadap pasien. Berwujud (tangibles), adalah kebersihan dan kenyamanan ruang tunggu serta kerapihan petugas (Parasuraman, 2017).

$$
\text { Menurut penelitian yang }
$$

dilakukan oleh Amirudin dkk, (2011) terdapat pengaruh positif antara pemberian informasi obat terhadap kepuasan pasien saat menebus obat. Penelitian oleh Imas dan Wahyuningsi (2016), menyatakan $85 \%$ pasien merasa puas terhadap keramahan yang ditunjukkan oleh petugas. Pasien merasa dihargai dan diperhatikan oleh petugas, sehingga hal ini akan membuat pasien mau kembali lagi untuk menggunakan jasa rumah sakit. Penelitian yang dilakukan oleh Arimbawa (2014), bahwa kecepatan pelayanan berhubungan secara signifikan terhadap kepuasan pasien. Kecepatan pelayanan sendiri adalah target pelayanan yang dapat diselesaikan dengan waktu yang telah ditentukan oleh unit penyelenggara pelayanan dengan tujuan tercapainya kepuasan pasien. Kecepatan petugas dalam pelayanan menurut waktu tunggu pelayanan resep racikan yang ideal adalah 25 menit (Isnanto dkk, 2011). Waktu tunggu pelayanan resep non racikan 15 menit (Harijono, 2011).

Hasil wawancara singkat peneliti kepada beberapa pasien rawat jalan yang menunggu mengeluhkan waktu tunggu yang lumayan lama untuk mendapatkan obat, obat yang dibutuhkan tidak tersedia di instalasi farmasi sehingga mengharuskan pasien menebus obat di apotik lain dan ruang tunggu yang terbatas. Mengingat peran instalasi farmasi yang penting bagi rumah sakit, maka sudah selayaknya bahwa rumah sakit menaruh perhatian yang lebih terhadap peningkatan mutu pelayanan di instalasi farmasi rumah sakit agar pasien tidak beralih menebus obat di apotik lain. Oleh karena itu, dilakukan penelitian tentang kepuasan pasien rawat jalan terhadap pelayanan yang di berikan untuk mengetahui kepuasan pasien.

\section{METODOLOGI PENELITIAN \\ Tempat dan Waktu Penelitian}

Penelitian ini dilakukan pada bulan Juli-September 2019 di Instalasi Farmasi Rumah Sakit Bhayangkara Manado.

\section{Populasi dan Sampel Penelitian}

Populasi dalam penelitian ini yaitu pasien rawat jalan periode bulan Maret - Mei 2019 sebanyak 3.000 pasien. Sampel pada penelitian ini ditentukan dengan kriteria inklusi dan eksklusi.

\section{Teknik Pengambilan Sampel}

Teknik pengambilan sampel menggunakan metode purposive sampling yakni teknik sampling non random, dimana peleliti menetapkan ciriciri khusus yang sesuai dengan tujuan penelitian.

Perhitungan sampel menggunakan rumus Slovin :

$$
\begin{aligned}
n & =\frac{N}{1+N e^{2}} \\
& =\frac{3.000}{\left\{1+\left(3.000 \times 0,05^{2}\right)\right\}} \\
& =\frac{3.000}{1+7,5}=\frac{3.000}{8,5} \\
& =352,94=353
\end{aligned}
$$

Keterangan :

$n=$ Ukuran Sampel

$\mathrm{N}=$ Ukuran Populasi

$\mathrm{e}=$ Penelitian menggunakan derajat kepercayaan $95 \%$ maka tingkat kesalahan dalam penelitian ini adalah $5 \%$ atau 0,05 (Sugiyono, 2013).

\section{Uji Validitas dan Uji Reliabilitas}

Uji validitas merupakan suatu alat pengukuran untuk mengukur apa yang diukur guna menunjukan tingkat 
kesahihan suatu instrumen (Dahlan, 2010). Alat ukur yang digunakan dalam penelitian ini adalah kuisioner. Sebelum kuisioner digunakan dalam penelitian, kuisioner dilakukan uji validalitas terlebih dahulu dengan rumus $r$ product moment. Kuisioner dinyatakan valid jika $r_{\text {hitung }} \geq$ $r_{\text {tabel }}$ (Dahlan, 2012).

Uji validalitas sebuah kuisioner penelitian dapat dilakukan dengan menguji 30 responden (Rangkuti, 2009). Uji validalitas sebanyak 30 responden dengan taraf signifikan 5\%, maka nilai $r_{\text {tabel }}$ adalah 0,361 (Sugiyono, 2016).

Reliabilitas adalah indeks yang menunjukan sejauh mana suatu alat pengukur dapat dipercaya atau dapat diandalkan. Bila suatu alat pengukur dipakai dua kali untuk mengukur gejala yang sama dan hasil pengukuran yang diperoleh relative konsisten, maka alat pengukur tersebut reriabel. Dengan kata lain reliabilitas menunjukan konsistensi suatu alat pengukuran didalam mengukur suatu gejala yang sama (Sugiyono, 2016).

Pengukuran reliabilitas menggunakan bantuan software computer dengan rumus Alpha Cronbach. Suatu variabel dikatakan reabibel jika memberikan nilai Alpha Cronbach > 0,60 (Budiman, 2013).

\section{Analisis Data}

Penelitian ini menggunakan metode SERVQUAL. Metode ini dibangun atas adanya perbandingan dua faktor utama, yaitu persepsi pelanggan atas layanan yang nyata mereka terima (perceived service) dengan layanan yang sesungguhnya mereka harapkan (expected service). (Subiyakno, 1999).

Atribut pernyataan yang ada dalam kuesioner ini sama, hanya skala yang berbeda. Yaitu pada bagian harapan menggunakan skala sangat tidak penting $=1$, tidak penting $=2$, cukup penting $=3$, penting $=4$ dan sangat penting $=5$. Sedangkan pada bagian kenyataan menggunakan skala sangat tidak memuaskan $=1$, tidak memuaskan $=2$, cukup memuaskan $=3$, memuaskan $=4$ dan sangat memuaskan $=5$.

Tingkat kesesuaian merupakan hasil perbandingan antara skor dari kinerja dengan skor dari kepentingan. Tingkat kesesuaian digunakan untuk menentukan skala prioritas layanan dan prioritas perbaikan yang mencapai kepuasan siswa. Berikut rumus perhitungan tingkat kesesuaian. Analisis yang digunakan untuk menghitung total kualitas pada penelitian ini menggunakan model Weighted Servqual sebagai berikut :

$$
I k j=\sum_{I=0}^{n}(P i j-E i j)
$$

Keterangan:

$I k j=$ Indeks total kualitas pelayanan

P $i j=$ Performance (kenyataan pada objek)

$E i j=$ Expectance $($ harapan atribut pada objek)

$n=$ Jumlah pernyataan

\section{HASIL DAN PEMBAHASAN}

Karakteristik responden pada penelitian ini dibagi ke dalam 5 kelompok yaitu usia, jenis kelamin, pendidikan, pekerjaan dan penanggung biaya dapat dilihat pada Tabel 1 .

Tabel 1. Karakteristik Responden

\begin{tabular}{|c|c|c|}
\hline Karakteristik Responden & Iucolah Responden (n) & Persentase $(\%)$ \\
\hline \multicolumn{3}{|l|}{ Ingia } \\
\hline Rexaja Ahir $17-25$ Tahun & 71 & $20 \%$ \\
\hline Deviasa Arval 26 - 35 Iahun & 129 & $37 \%$ \\
\hline Devxasa Ahix $36-45$ Tahun & 78 & $22 \%$ \\
\hline Iansia Axal $46-55$ Tahun & 57 & $16 \%$ \\
\hline Langia Ahir 56 - 65 Tahum & 18 & $5 \%$ \\
\hline \multicolumn{3}{|l|}{ Ienis Kelanin } \\
\hline Iaki-laki & 152 & $43 \%$ \\
\hline Pererguan & 201 & $57 \%$ \\
\hline \multicolumn{3}{|l|}{ Pendidikan } \\
\hline Tanat SD & 8 & $2 \%$ \\
\hline Ianat SMP & 47 & $14 \%$ \\
\hline Iamat SNCA & 145 & $41 \%$ \\
\hline $\mathrm{S1} / \mathrm{S} 2$ & 128 & $36 \%$ \\
\hline Lainnya & 25 & $7 \%$ \\
\hline \multicolumn{3}{|l|}{ Pokerjasan. } \\
\hline $\begin{array}{l}\text { PNS / Guru / Ini / Rolisi/ } \\
\text { Ienagr Kerehatan }\end{array}$ & 82 & $23 \%$ \\
\hline Wiraryata & 55 & $16 \%$ \\
\hline Syrasta & 121 & $34 \%$ \\
\hline Iou Rumah Tangga & 46 & $13 \%$ \\
\hline Belura Beverjaz & 32 & $9 \%$ \\
\hline Dokefjasn L ainnya & 17 & $5 \%$ \\
\hline \multicolumn{3}{|l|}{ Penangang biays } \\
\hline BPJS / Kantor & 330 & $93 \%$ \\
\hline Ianggungan Pribadi & 23 & $7 \%$ \\
\hline
\end{tabular}

Hasil penelitian menunjukan responden terbanyak berjenis kelamin perempuan yakni 201 pasien (57\%), dan jenis kelamin laki-laki sebanyak 152 pasien (43\%). Menurut Hermawan (2007), dari hasil penelitian yang dilakukan menunjukan bahwa jenis kelamin tidak menunjukan adanya hubungan yang signifikan dengan kepuasan pasien. Kenyataan dan reaksi dipengaruhi oleh ras, pendidikan kelas ekonomi dan latar belakang budaya. Peryataan tersebut antara laki-laki dan perempuan akan relatif sama dalam merasakan kepuasan

Kareakteristik responden berdasarkan usia yang terbanyak pada penelitian ini yaitu usia dewasa awal 
sebanyak 129 responden dengan persentase $37 \%$ dan yang terendah adalah usia lansia akhir sebanyak 18 responden dengan persentase 5\%. Menurut Hidayati (2014), dari hasil penelitian menunjukan tidak ada hubungan antara umur dengan tingkat kepuasan dimungkinkan karena pada dasarnya setiap pasien dari yang muda maupun yang tua menginginkan perhatian, setiap keluhannya ingin di dengar oleh tenaga kesehatan khususnya dokter dan perawat.

Kareakteristik responden berdasarkan pendidikan yang terbanyak pada penelitian ini yaitu responden lulusan SMA sebanyak 145 responden (41\%) dan diikuti oleh responden dengan lulusan S1/S2 sebanyak 128 responden (36\%). Hasil penelitian menunjukan pekerjaan yang terbanyak yaitu swasta sebanyak 121 responden (34\%) dan diikuti oleh PNS / Guru / TNI / Polisi / Tenaga Kesehatan sebanyak 82 responden $(23 \%)$. Karakteristik pasien berdasarkan penanggung biaya yang terbanyak adalah askes / BPJS / kantor yaitu 330 responden (93\%), dan kelompok dengan tanggungan pribadi sebanyak 23 responden (7\%). Menurut Wijono (1999) seseorang yang membayar untuk suatu produk cenderung lebih banyak menuntut atau berharap produk yang dibeli memang berkualitas dibandingkan dengan seseorang yang mendapat produk secara gratis. Menurut Lumenta (1989), kelompok masyarakat yang bekerja cenderung dipengaruhi oleh lingkungan pekerjaan juga lingkungaan keluarga. Seseorang yang bekerja cenderung lebih banyak menuntut atau mengkritik terhadap pelayanan yang diterima.

\section{Uji Validitas dan Uji Reliabilitas}

Uji validitas untuk kuisioner harapan dan kenyataan diberikan pada 30 responden pada awal penelitian. Kuisioner yang diberikan berisi 22 item pernyataan yang mewakili dari dimensi berwujud, kehandalan, ketanggapan, jaminan dan empaty. Data yang diperoleh akan dimasukan dalam lembar kerja SPSS dan diuji validitas. Nilai $r$ hitung hasil uji validitas dengan menggunakan SPSS selanjutnya dibandingkan dengan nilai $r$ tabel yaitu 0,360 (Priyatno, 2010). Berdasarkan hasil dari aplikasi statistik, dapat disimpulkan bahwa item semua item valid karena nilai $r$ hitung melebihi nilai $r$ tabel, sehingga seluruh pernyataan yang ada pada instrumen penelitian ini bisa disebarkan untuk responden sesuai dengan jumlah sampel penelitian.

Setiap item pernyataan yang telah dinyatakan valid, selanjutnya dilakukan uji reliablitas dan dilihat nilai Cronbach's Alpha. Kuisioner harapan dan kuisioner kenyataan dinyatakan reliabel dilihat dari nilai koefisien Cronbach's Alpha $(>0,6)$. Kuisioner kenyataan 0.883 dan kuisioner harapan 0.883. Berdasarkan ketentuan tersebut maka kuesioner bagian kinerja yang dibuat sudah reliabel.

\section{Perhitungan Nilai SERVQUAL}

Perbedaan antara harapan dan kenyataan atas suatu kualitas pelayanan yang diterima oleh siswa inilah yang disebut dengan kesenjangan atau gap. Skor SERVQUAL dihiting dengan = Ratarata Kenyataan - Rata-rata Harapan. Perhitungan nilai SERVQUAL ke 5 dimensi dapat dilihat pada Tabel 2.

Tabel 2. Perhitungan Nilai SERRQUAL ke 5 Dimensi.

\begin{tabular}{|c|c|c|c|}
\hline \multicolumn{4}{|l|}{ BERWUJUD (TANGIBLE) } \\
\hline Peruyataan & Kenyataan & $\underset{\text { Harapa }}{\text { Ha }}$ & Gap \\
\hline 1. Ruangan bersh dan raph & 4.168 & 4.776 & -0.608 \\
\hline 2. Petugas berpakaian rapith & 4261 & 4.613 & -0.351 \\
\hline 3. Ruang instalasi famas terasa nyaman & 4.097 & 4.761 & -0.665 \\
\hline $\begin{array}{l}\text { 4. Tersedianya informasi obat dalam berntk } \\
\text { brosur }\end{array}$ & 4219 & 4.665 & -0.946 \\
\hline 5. Terdapat petunjuk nuangan & 4526 & 4.784 & -0.259 \\
\hline Rata-Rata & 4.154 & 4.720 & -0.566 \\
\hline \multicolumn{4}{|l|}{ KEHANDALAN (RELIABILIT) } \\
\hline No $\quad$ Pernyataan & Kenyataan & Harapan & Gap \\
\hline $\begin{array}{l}\text { 6. Petugas memberinformasi tentang } \\
\text { nama obat }\end{array}$ & 4.460 & 4991 & -0.531 \\
\hline $\begin{array}{l}\text { 7. Petugas menaberi informasi temtang } \\
\text { dosis cbat }\end{array}$ & 4.460 & 4.886 & -0.426 \\
\hline $\begin{array}{l}\text { 8. Petugas memberi informasi tentang } \\
\text { cara pemakaim obat }\end{array}$ & 4.435 & 4.886 & -0.452 \\
\hline $\begin{array}{l}\text { 9. Petugas memberi informasi tentang } \\
\text { cara penyimpanan obat: }\end{array}$ & 4.136 & 4.801 & -0.665 \\
\hline $\begin{array}{l}\text { 10. Petugas menyampaikan efek sampring } \\
\text { obat setelah di minum }\end{array}$ & 4.134 & 4.875 & -0.741 \\
\hline $\begin{array}{l}\text { 11. Pelayanan informasi obat } \\
\text { menggunakan bahasa yang bisa di } \\
\text { mengerti pasien }\end{array}$ & 4.506 & 4.849 & -0.344 \\
\hline 12. Petugas cepat dalam pelayanan & 4.719 & 4.906 & -1.188 \\
\hline Rata-Rata & 4.264 & 4.885 & -0.621 \\
\hline
\end{tabular}




\begin{tabular}{|c|c|c|c|c|}
\hline & $\begin{array}{l}\text { KETANGGAPAN } \\
\text { (RESPONSIVENESS) }\end{array}$ & & & \\
\hline No & Pernyataan & Kenyataan & Harapan & Gap \\
\hline 13. & $\begin{array}{l}\text { Petugas menjawab dengan tanggap } \\
\text { saat pasien bertanya }\end{array}$ & 4.290 & 4.841 & -0.551 \\
\hline 14. & $\begin{array}{l}\text { Petugas menangani keluhan pasien } \\
\text { dan di tangani dengan cepat }\end{array}$ & 4.955 & 4.889 & -0.935 \\
\hline \multirow[t]{3}{*}{15.} & $\begin{array}{l}\text { Petugas memberi peragaan obat tanpa } \\
\text { pasien harus meminta }\end{array}$ & 4.960 & 4.793 & -0.832 \\
\hline & Rata-Rata & 4.068 & 4.841 & -0.773 \\
\hline & JAMINAN (ASSURANCE) & & & \\
\hline No & Penyyatan & Kenyataan & Harapan & Gap \\
\hline 16. & $\begin{array}{l}\text { Obat yang diberikan sesuai dengan yang } \\
\text { diminta pasein }\end{array}$ & 4.688 & 4.918 & -0.230 \\
\hline 17. & Obat yang diberikan terjamin kualitasnya & 4.710 & 4.946 & -0.236 \\
\hline 18. & $\begin{array}{l}\text { Instalasi Farmasi menyediakan obat- } \\
\text { obatan yang lengkap }\end{array}$ & 4.000 & 4.920 & -0.920 \\
\hline 19. & $\begin{array}{l}\text { Petugas memiliki pengetahuan dan } \\
\text { keterampilan yang baik dalam bekerja }\end{array}$ & 4.545 & 4.929 & -0.384 \\
\hline Rata-1 & & 4.486 & 4.928 & .0 .442 \\
\hline
\end{tabular}

EMPATI (EMPHATI)

\begin{tabular}{|c|c|c|c|c|}
\hline No & Penyataan & Kenyataan & Harapan & Gap \\
\hline 20. & $\begin{array}{l}\text { Petugas bersikap ramah dan sopan dalam } \\
\text { memberikan informasi obat }\end{array}$ & 4.520 & 4.824 & -0.34 \\
\hline 21. & $\begin{array}{l}\text { Petugas memberikan perhatian yang } \\
\text { sama terhadap semua pasien }\end{array}$ & 4.500 & 4.815 & -0.315 \\
\hline 22. & $\begin{array}{l}\text { Petugas memberikan kesempatan kepada } \\
\text { pasien untuk bertanya atau } \\
\text { menyampaikan keluhan }\end{array}$ & 4.384 & 4.824 & -0.440 \\
\hline & Rata-Rata & 4.468 & 4.821 & -0.353 \\
\hline
\end{tabular}

Kuisioner pada dimensi tangibles diwakili oleh 5 butir pernyataan. Kepuasan pasien dilihat dari dimensi tangibels secara keseluruhan belum memuaskan pasien, karena nilai rerata dimensi yaitu -0.26 . Berdasarkan analisa, seharusnya item 3 yaitu ruang instalasi terasa nyaman dan 4 tersedianya informasi obat dalam bentuk brosur. Pihak rumah sakit harus memperbaiki kualitas ruangan dengan menambah fasilitas seperti tempat duduk dan pendingin ruangan serta melengkapi fasilitas yang memadai dan mendukung di Instalasi Farmasi seperti disediakannya brosur obat sehingga pasien dapat mengisi waktu saat mengantri obat.

Hasil penelitian pada dimensi reliability diwakili oleh 6 butir pernyataan. Secara keseluruhan dimensi reliability menunjukan angka -0,86 yang berarti pasien belum puas. Hal itu disebabkan karena banyaknya pasien yang mengantri sehingga petugas di Instalasi tidak menjelaskan lagi tentang dosis, cara pemakaian obat, cara penyimpanan obat hingga efek samping obat yang diberikan kepada pasien. Sesuai dengan Permenkes nomor 72 tahun 2016, beban kerja apoteker di Instalasi Farmasi Rumah Sakit yaitu rasio 1 apoteker untuk 50 pasien rawat jalan. Dilihat pada jumlah apoteker yang bertugas di Instalasi Farmasi Rumah
Sakit Bhayangkara Manado terdiri dari 2 orang apoteker, yang tidak sesuai dengan standar, kenyataan pelayanan obat dengan jumlah apoteker yang memberikan pelayanan sedikit sedangkan pasien banyak yang mengantri, seharusnya pihak rumah sakit dapat menambah jumlah apoteker.

Kuisioner pada dimensi responsiveness diwakili oleh 3 butir pernyataan. Diketahui nilai Ikj terendah pada item 13 yaitu petugas menjawab dengan tanggap saat pasien bertanya. Pasien merasa belum puas di karenakan jawaban dari petugas dianggap kurang jelas. Instalasi Farmasi Rumah Sakit seharusnya dapat memperhatikan para petugasnya khususnya apoteker dalam memberikan resep kepada pasien agar bisa di jelaskan dengan baik sehingga akan memuaskan pasien jika bisa langsung berkomunikasi dengan apoteker.

Pada dimensi assurance mencapai nilai keseluruhan nrata-rata Ikj sebesar 0,305 . Nilai ini memberikan gambaran pasien tidak puas akan kinerja di Instalasi farmasi. Pasien belum puas pada dimensi ini karena pada kenyataan instalasi farmasi belum menyediakan obat-obatan yang lengkap sehingga tidak jarang pasien harus menebus resep di apotik lain, secara tidak langsung memperlambat pasien untuk memperoleh resep yang dibutuhkan.

Kuisioner pada dimensi empathy di wakili oleh 3 pernyataan, nilai Ikj terendah pada terletak pada item 21 dengan angka $(-0,31)$ dan secara keseluruhan pasien belum puas dengan dimensi empati. Hal ini disebabkan karena banyak pasien yang menunggu antrian sehingga petugas tidak memberikan informasi tentang obat yang diminta pasien agar cepat dalam pelayanan. Rumah Sakit seharusnya memberbaiki dengan menambahkan tenaga kerja apoteker pada Instalasi Farmasi agar pemberian informasi obat kepada pasien berjalan dengan baik dan pasien tidak membutuhkan waktu tunggu yang terlalu lama.

Berdasarkan nilai indeks total kepuasan pasien masing-masing menunjukkan nilai negatif, ini menunjukkan kenyataannya masih ada ketidaksesuaian yang dirasakan pasien yang masih menuntut petugas di Instalasi Farmasi untuk memberikan pelayanan yang mengedepankan perhatian secara pribadi kepada pasien. 


\section{KESIMPULAN}

Tingkat kepuasan pasien terhadap pelayanan yang diberikan di Instalasi Farmasi Rumah Sakit Bhayangkara Manado berdasarkan nilai kepuasan secara keseluruhan berada pada indeks negatif, secara berturut-turut yaitu reliability (-0.86), responsiveness ($0.69)$, emphaty (-0.37), assurance (0-305) dan yang terendah adalah tangible (-0.26) artinya bahwa pasien belum merasa puas terhadap pelayanan yang diberikan di Instalasi Farmasi Rumah Sakit Bhayangkara Manado.

\section{SARAN}

Berdasarkan hasil penelitian yang telah dilakukan, diharapkan pihak Rumah Sakit Bhayangkara Manado khususnya Instalasi Farmasi untuk dapat fokus pada perbaikann mutu pelayanan instalasi farmasi, serta menjadikan prioritas utama permasalahan yang di anggap penting bagi pasien.

\section{DAFTAR PUSTAKA}

Amirudin, R. Jafar, N. Perdana, N. Sulistyawati, M dan Syafar, M. 2011. Hubungan Kualitas Pelayanan Farmasi Rawat Jalan terhadap Kepuasan dan Keputusan Beli Ulang Obat Di IFRS Jala Ammari Makasar. Fakultas FKM Universitas Hasanuddin Makassar

Arimbawa, P.E. 2014. Hubungan Pelayanan Kefarmasian Dengan Kepuasan Pasien Menggunakan Jasa Apotek di Kota Denpasar [Tesis]. Universitas Udayana. Bali

Budiman, A. R. 2013. Pengetahuan dan Sikap dalam Penelitian Kesehatan. Salmeba Medika. Jakarta

Dahlan, S. M. 2010. Besar Sampel dan Cara Pengambilan Sampel dalam Penelitian Kedokteran dan Kesehatan. Salemba Medika. Jakarta

Dahlan, S. M. 2012. Statistik Untuk Kedokteran dan Kesehatan Edisi Keempat. Salemba Medika. Jakarta
Harijono, H. Soepangkat, BO. 2011. Upaya Peningkatan Kualitas Layanan Farmasi RSK. St Vincentius A Paulo Surabaya Dengan Menggunakan Metode SEVQUAL dan QFD.Prosiding Seminar Nasional Manajemen Teknologi XIV Program Studi MMT-ITS. Surabaya

Hermawan, Asep. 2007. Pengembangan Kurikulum dan Pembelajaran. Universitas Terbuka. Jakarta

Imas, N.R. Wahyuningsih, S. 2016. Faktor Pelayanan Kefarmasian dalam Peningkatan Kepuasan PAsien di Pelayanan Kesehatan. IJMS - Indonesian Journal On Medical Science. Vol 3, No 1

Isnanto, R.R. Sofwan, A. Suwaryo. 2011. Simulasi SIstem Pelayanan Resep Pada Apotek Berprioritas Banyak Loket. UNDIP. Semarang

Lumenta, Bejamin. 1989. Pelayanan Medis Citra, Konflik dan Harapan. Penerbit Kanisius. Yogyakarta

Parasuraman. A. 1998. SERVQUAL: A Multiple Item Scale for Measuring Consumer Perception of Service Quality. International Journal for Quality in Health Care, Vol 25. No 6 h. 696-703

Priyatno, D. 2010. Teknik Mudah dan Cepat Melakukan Analisis Data Penelitian dengan SPSS dan Tanya Jawab Ujian Pendadaran. Gaya Media. Yogyakarta

Subiyakno, H.H. 1999. Ukuran Kualitas Jasa : Gap Antara Kinerja dan Harapan. Jurnal Marketing. Vol 2, No. 1

Sugiyono. 2016. Metode Penelitian Kuantitatif Kualitatif dan $R \& D$. Alfabeta. Bandung

Wijono, D. 1999. Manajemen Mutu Pelayanan kesehatan. Airlangga University Press. Surabaya. 